\title{
Accumulation of the Mycotoxin Patulin in the Presence of Gluconic Acid Contributes to Pathogenicity of Penicillium expansum
}

\author{
Shiri Barad, ${ }^{1,2}$ Sigal Brown Horowitz, ${ }^{1}$ Ilana Kobiler, ${ }^{1}$ Amir Sherman, ${ }^{3}$ and Dov Prusky ${ }^{1}$ \\ ${ }^{1}$ Department of Postharvest Science of Fresh Produce, ARO, The Volcani Center, Bet Dagan 50250, Israel; ${ }^{2}$ Department of \\ Plant Pathology and Microbiology, The Robert H. Smith Faculty of Agriculture, Food and Environment, The Hebrew University \\ of Jerusalem, Rehovot 76100, Israel; and ${ }^{3}$ Genomics Unit, ARO, The Volcani Center, Israel
}

Submitted 12 May 2013. Accepted 28 August 2013.

Penicillium expansum, the causal agent of blue mold rot, causes severe postharvest fruit maceration through secretion of D-gluconic acid (GLA) and secondary metabolites such as the mycotoxin patulin in colonized tissue. GLA involvement in pathogenicity has been suggested but the mechanism of patulin accumulation and its contribution to $P$. expansum pathogenicity remain unclear. The roles of GLA and patulin accumulation in $P$. expansum pathogenicity were studied using i) glucose oxidase GOX2-RNAi mutants exhibiting decreased $G O X 2$ expression, GLA accumulation, and reduced pathogenicity; ii) $I D H$-RNAi mutants exhibiting downregulation of $I D H$ (the last gene in patulin biosynthesis), reduced patulin accumulation, and no effect on GLA level; and iii) PACC-RNAi mutants exhibiting downregulation of both $G O X 2$ and $I D H$ that reduced GLA and patulin production. Present results indicate that conditions enhancing the decrease in GLA accumulation by GOX2RNAi and $P A C C$-RNAi mutants, and not low $\mathrm{pH}$, affected patulin accumulation, suggesting GLA production as the driving force for further patulin accumulation. Thus, it is suggested that GLA accumulation may modulate patulin synthesis as a direct precursor under dynamic pH conditions modulating the activation of the transcription factor $P A C C$ and the consequent pathogenicity factors, which contribute to host-tissue colonization by $P$. expansum.

Penicillium expansum is a destructive phytopathogen that causes decay in deciduous fruit during postharvest handling and storage. The pathogen is not considered to be host specific among deciduous fruit and typically causes extensive maceration of the infected tissue, presumably by a common mechanism of tissue acidification (Prusky et al. 2004). Direct tissue acidification is achieved by its secretion of organic acids, mainly D-gluconic acid (GLA) (Hadas et al. 2007; Prusky and Yakoby 2003; Prusky et al. 2004).

Nucleotide sequence data for GOX2, IDH, and PACC of Penicillium expansum are available in the GenBank database under accession numbers GQ324948 (GOX2), DQ084388 (IDH), and AY225524 (PACC).

Correspondence author: D. Prusky; Telephone: +972-3-9683610/3880; Fax: +972-3-9683622; E-mail: dovprusk@ volcani.agri.gov.il

* The $\boldsymbol{e}$-Xtra logo stands for "electronic extra" and indicates that one supplementary figure is published online and Figure 1 appears in color online.

(C) 2014 The American Phytopathological Society
In Penicillium spp., pathogenicity has been attributed to, among other things, the secretion of polygalacturonases which depolymerize pectin, thereby causing tissue maceration (Sánchez-Torres and González-Candelas 2003; Yao et al. 1996). Expression of PEPG1, which encodes a polygalacturonase, is upregulated under the acidic conditions resulting from GLA accumulation (Prusky et al. 2004). In P. expansum, oxidation of $\beta$-D-glucose to D-glucono- $\delta$-lactone and $\mathrm{H}_{2} \mathrm{O}_{2}$ is catalyzed by glucose oxidase (GOX) (Bruchmann et al. 1987; Kobayashi et al. 1998; Prusky et al. 2004). Previous studies by Hadas and associates (2007) identified two putative genes (GOX1 and GOX2) involved in the production of GLA but concluded that GOX2 is the most important one for $P$. expansum pathogenicity (Hadas et al. 2007). GLA accumulation by $P$. expansum is $\mathrm{pH}$ dependent and is mainly regulated by GOX2 expression, with highest expression under neutral and alkaline conditions ( $\mathrm{pH} 7.0$ to 9.0) compared with acidic conditions ( $\mathrm{pH} 4.0$ ). Barad and associates (2012) used a transgenic approach to analyze the contribution of GOX2 to the acidification process and pathogenicity. Functional analysis of GOX2RNAi mutants showed that modulation of GLA level strongly affects pathogen interactions with the host: the greater the downregulation of GOX2 in the GOX2-RNAi mutants, the stronger the impairment in GLA production, medium acidification, and apple fruit infection. Those results further supported the hypothesis that $P$. expansum's ability to acidify the environment results in the expression of genes and secretion of hydrolytic enzymes that contribute to pathogenicity (Prusky et al. 2004).

Other approaches used to functionally analyze the contribution of GOX2 to pathogenicity involved its heterologous expression in $P$. chrysogenum, a pathogen of nondeciduous fruit. Barad and associates (2012) reported that expression of $P$. expansum GOX2 in $P$. chrysogenum enhances GLA production, acidification of the medium, surface colonization, and production of conidia on susceptible pear fruit discs; however, fruit colonization was attenuated compared with the wild-type (WT) P. expansum strain Pe-21. These results indicated that the observed increase in GLA production is one factor promoting surface colonization and sporulation but complete pathogenicity still requires the expression of other pathogenicity factors which might be lacking in $P$. chrysogenum (MohammadSaeid et al. 2010; Qin et al. 2007). Qin and associates (2007) confirmed early work by Yao and associates (1996), in which the expression of three polygalacturonase proteins was found to be repressed under attenuated virulence conditions, suggesting that these enzymes contribute to fungal virulence. However, 
there is still only a limited amount of research on the possible secretory proteins contributing to $P$. expansum virulence.

The mycotoxin patulin is a key secreted product that always accumulates in colonized tissue during $P$. expansum colonization, to concentrations of 16,000 to $44,000 \mu \mathrm{g} \mathrm{kg}^{-1}$ (Piemontese et al. 2007; Puel et al. 2010). Patulin is one of a short list of mycotoxins (aflatoxin, ochratoxin A, zearalenone, fumonisins, and trichothecenes) whose levels in food are regulated in many countries around the world because of their toxic effects to people, particularly children (Puel et al. 2010). The biosynthetic pathway of patulin - a polyketide metabolite-includes more than 10 steps (Sekiguchi and Gaucher 1977).

The high accumulation of patulin in decaying tissue during the acidification process raised the question of its biological role in $P$. expansum pathogenicity. Published reports could not reach a conclusion on the importance of patulin as a pathogenicity factor. Although patulin was isolated from more than 30 species belonging to the genera Penicillium, Aspergillus, Paecilomyces, and Byssochlamys, the mycotoxin only occurred in $P$. expansum-colonized fruit. Furthermore, patulin-producing strains of $P$. expansum isolated from a variety of host fruit, including apricot, black mulberry, cherry, kiwi, nectarine, plum, strawberry, and white mulberry, induced levels of patulin accumulation that varied up to sixfold $\left(1,800\right.$ to $\left.12,500 \mu \mathrm{g} \mathrm{kg}^{-1}\right)$ (Demirci et al. 2003; Larsen et al. 1998; Leggott and Shephard 2001; Lugauskas et al. 2005; Reddy et al. 2010; Ritieni 2003) in one single apple host. Furthermore, a single isolate inoculated on a different host induced the production of different levels of patulin (from 150 to $11,200 \mu \mathrm{g} \mathrm{kg}^{-1}$ ), suggesting a differential pattern of production depending on the host and temperature, $\mathrm{pH}$, and other chemical characteristics intrinsic to fruit-storage conditions. A few reports have described a relationship between colonization and toxin accumulation. McCallum and associates (2002) isolated different $P$. expansum isolates which showed varying levels of patulin production, from 0 to $6,000 \mu \mathrm{g}$ per gram of dry weight of apple tissue. The highest patulin levels were produced by isolates displaying aggressive growth and rapidly increasing acidity of the medium, accompanied by profuse mycelial development. Furthermore, Sanzani and associates (2012) reported that knock out of 6-methylsalicylic acid synthase (6-MSAS), one of the first genes in the biosynthetic pathway of patulin, reduces pathogenicity by 40 to $50 \%$. All of these results suggest that the association between patulin and pathogenicity under conditions of P. expansum colonization in fruit is not entirely clear.

Our hypothesis, based on our recent publication (Barad et al. 2012) and our present results, is that GLA production is the driving force for activation of patulin synthesis and, together, these compounds contribute to the enhanced pathogenicity of $P$. expansum in fruit. Using three different genetics approaches-i) $P$. expansum GOX2 mutants that show modulated GLA synthesis; ii) $P$. expansum mutants in $I D H$ (encoding isoepoxydon dehydrogenase, in the last stages of patulin synthesis) (Dombrink-Kurtzman 2007) affecting the production of patulin; and iii) $P$. expansum mutants in the transcription factor $P A C C$, affecting the biosynthesis of both GLA and patulin-we showed the importance of the acidification process caused by GLA accumulation in the induction of patulin biosynthesis and accumulation and in its contribution to $P$. expansum pathogenicity in colonized fruit. Our results indicate that GLA and patulin are pathogenicity factors of $P$. expansum modulated by the transcription factor PACC expressed during fruit colonization.
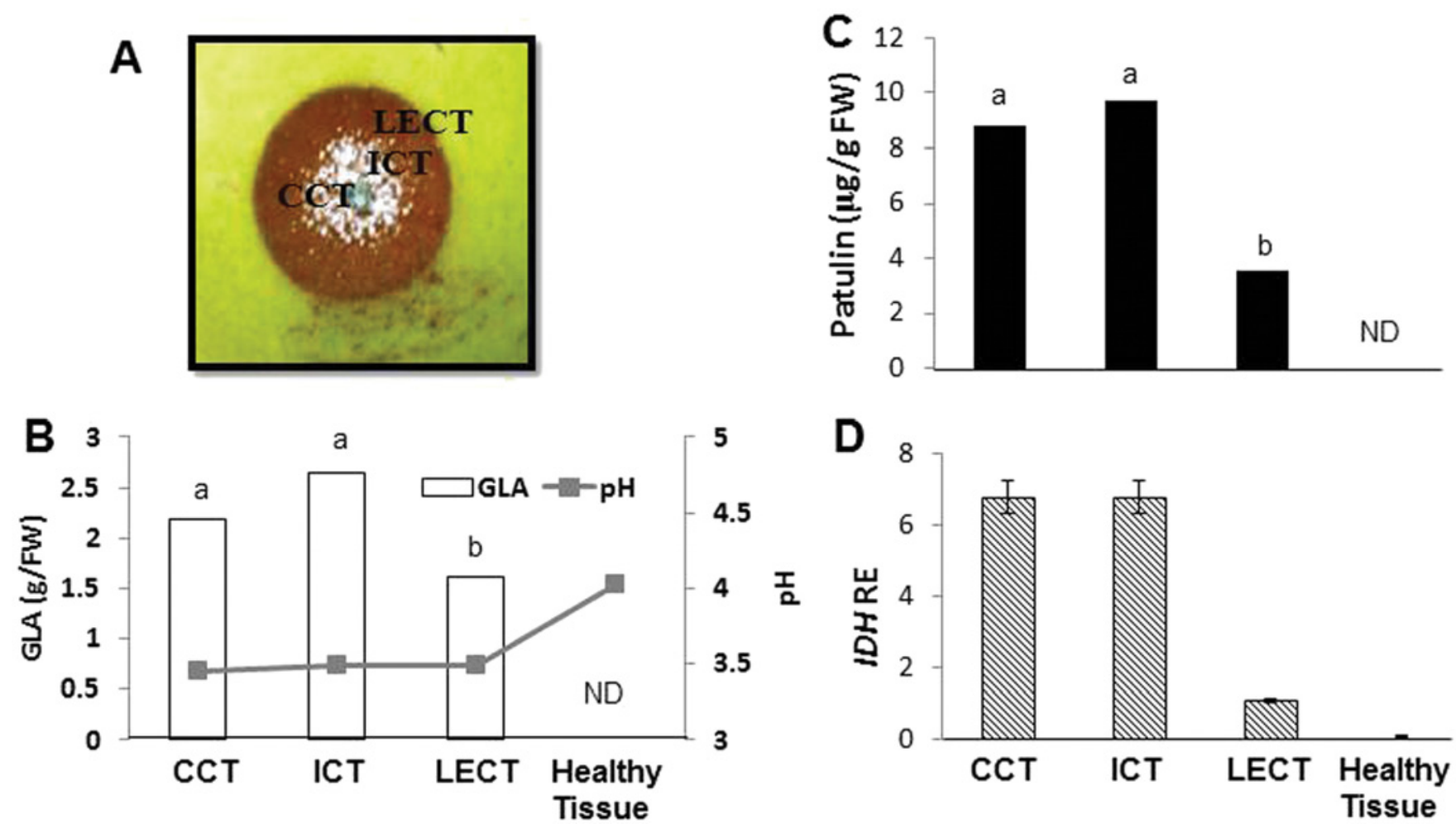

Fig. 1. D-gluconic acid (GLA) and patulin accumulation and relative $I D H$ expression in different areas of the decayed tissue of 'Golden Delicious' apple fruit inoculated with Penicillium expansum. The following parameters were measured in different regions of the decayed fruit: A, Colonized tissue; B, GLA accumulation; $\mathbf{C}$, patulin accumulation; $\mathbf{D}$, relative expression of $I D H$. Different values presented were extracted from the leading edge of the decayed tissue (LECT), intermediate colonized tissue (ICT), and the center of decay (CCT). Relative expression values of IDH are the averages of three replicates from three different RNA extractions from apple tissues compared with the LECT. Average values \pm standard error of three replicates of relative IDH expression are presented. Average values of three replicates of total GLA and patulin accumulation are also presented. Columns and symbols with different letters are significantly different at $P \leq 0.05$ according to the Tukey-Kramer multiple comparison test. Experiments were repeated three times, and the results of a single representative experiment are shown. 


\section{RESULTS}

GLA, pH, and patulin

in apple fruit tissue colonized by $P$. expansum.

Analysis of the decayed tissue colonized by $P$. expansum 5 days after inoculation showed central colonized tissue (CCT)

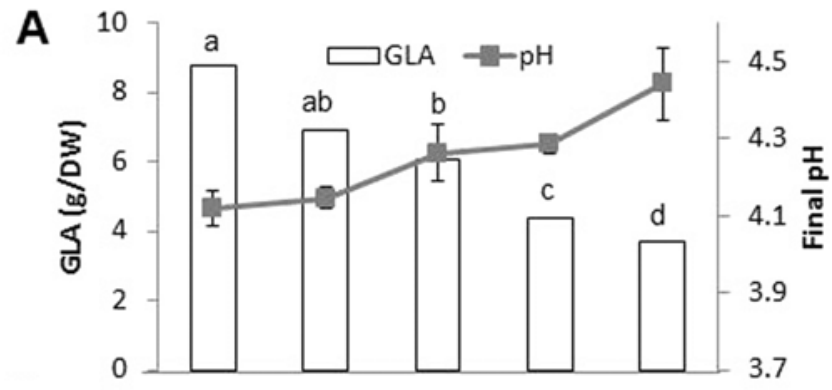

B
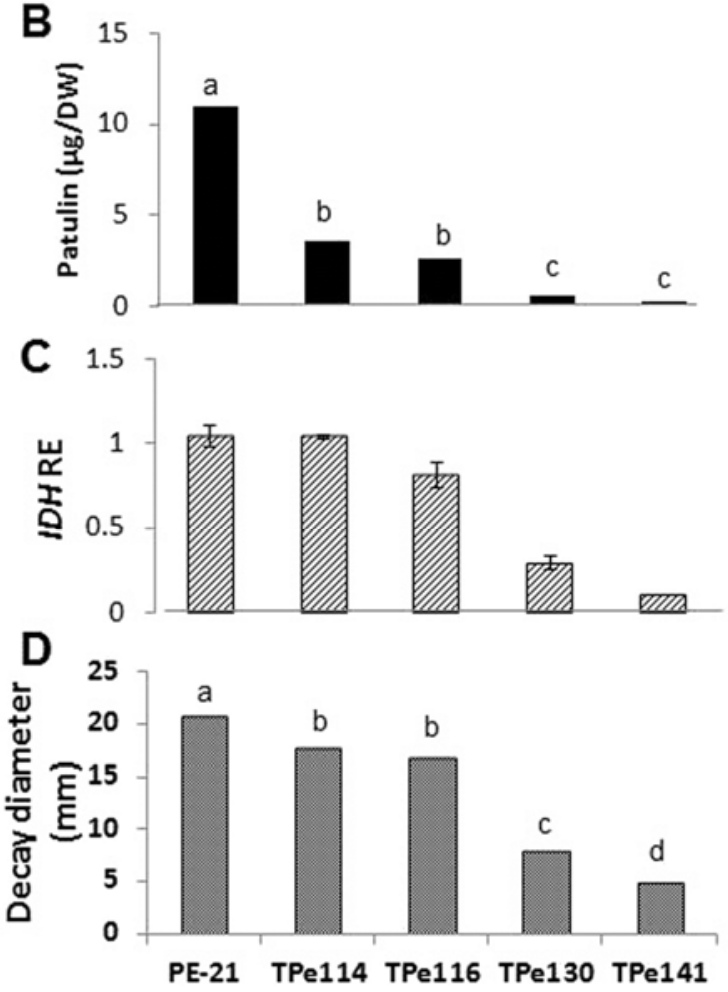

Fig. 2. Relationship between D-gluconic acid (GLA) and patulin accumulation and relative $I D H$ expression in GOX2-RNAi mutants of Penicillium expansum and their pathogenicity on 'Golden Delicious' apple fruit. Solid secondary medium at an initial $\mathrm{pH}$ of 7.0 was inoculated with $100 \mu \mathrm{l}$ of a spore suspension of $10^{6}$ spores $\mathrm{ml}^{-1}$ and the different parameters evaluated $48 \mathrm{~h}$ later by sampling five medium discs from five independent culture plates. A, GLA accumulation and final $\mathrm{pH}$ values; $\mathbf{B}$, patulin accumulation; $\mathbf{C}$, relative $I D H$ expression of GOX2-RNAi mutants compared with the wild-type strain; D, colonization diameter. Average values of five replicates are reported for relative $I D H$ expression ( \pm standard error), GLA, and patulin accumulation. For colonization, the average values presented were obtained from nine independent inoculation points. Columns and symbols with different letters are significantly different at $P \leq 0.05$ according to the Tukey-Kramer multiple comparison test. Experiments were repeated three times and the results of a single representative experiment are shown. with initial sporulation, and intermediate colonized tissue (ICT) up to the leading edge of the colony (LECT) followed by the healthy part of the apple (Fig. 1A). GLA concentration in the CCT and ICT was 2.2 to $2.6 \mathrm{~g}$ per gram of fresh weight (FW) and declined in the LECT to $1.6 \mathrm{~g}$ per gram of $\mathrm{FW}$, compared with no accumulation in the healthy flanking part of the colonized tissue (Fig. 1B). Patulin accumulation was also highest in the CCT and ICT, at 7.5 to $8.1 \mu \mathrm{g}$ per gram of FW, compared with $0.30 \mu \mathrm{g}$ per gram of $\mathrm{FW}$ and no accumulation in the LECT and healthy tissue, respectively, suggesting the occurrence of both GLA and patulin in the colonized tissue (Fig. 1C). Relative expression of $I D H$ showed a sevenfold increase in the CCT compared with the LECT (Fig. 1D). The $\mathrm{pH}$ of the healthy part of the apple tissue was 4.2 , declining to 3.5 in the CCT and ICT (Fig. 1B). The concomitant occurrence of GLA and patulin during fungal colonization raised the question of the mechanism underlying each metabolite's accumulation and these metabolites' contribution to pathogenicity. To answer this, we used a series of GOX2 mutants (Barad et al. 2012) that differed in their ability to accumulate GLA and in their consequent contribution to pathogenicity.

\section{GOX-RNAi mutants downregulate}

IDH expression and patulin accumulation.

To understand the effect of GLA accumulation on patulin production and pathogenicity, we used GOX2-RNAi mutants of $P$. expansum, which were differentially impaired in the secretion of GLA and pathogenicity (Barad et al. 2012). To determine whether downregulation of GOX2 in the GOX2-RNAi mutants (Table 1) modulates $I D H$ expression and patulin production, the WT strain Pe-21 and the mutant strains were grown on secondary medium (SM)-agar solid medium adjusted to an initial $\mathrm{pH}$ of 7.0 for 48 h (Fig. 2). Functional characterization of GOX2RNAi mutants showed significantly decreased production of GLA and consequent decrease of $\mathrm{pH}$ in the medium. In mutant strains $\mathrm{TPe}_{130}$ and $\mathrm{TPe}_{141}$, which showed $50 \%$ (4.3 g per gram of $\mathrm{DW}$ ) and $45 \%$ (3.8 g per gram of DW) decreased production of GLA, respectively, the $\mathrm{pH}$ declined from 7.0 to 4.3 and 4.45 , respectively, compared with 4.12 in the WT strain, with GLA at $8.7 \mathrm{~g}$ per gram of DW. An intermediate level of GLA and only partial decline in $\mathrm{pH}$ were observed for RNAi mutants $\mathrm{TPe}_{114}$ and $\mathrm{TPe}_{116}$ (Fig. 2A). Functional characterization of GOX2RNAi mutants also showed significant downregulation of $I D H$ expression and patulin accumulation, by a factor of approximately 10, during growth of $\mathrm{TPe}_{141}$ in $\mathrm{SM}$ (Fig. 2B and C). These findings indicate that the downregulation by GOX2-RNAi significantly decreases GLA and patulin production, suggesting that patulin regulation is largely dependent on the potential for GLA production and the resulting modification in $\mathrm{pH}$ (Fig. 2). To determine that the RNAi mutants did not suffer a broader effect on gene expression, we compared the relative expression of other genes from $P$. expansum, including pectin lyase (AY545054.1), pacC, calmodulin (DQ-911134.1), and $\beta$-tubulin (GN-872745.1), and their relative expression was not affected compared with the WT strain (results not shown). Analysis of the colonization pattern showed that downregulation of GLA and patulin accumulation significantly reduces the colonization of P. expansum mutants (Fig. 2D).

Table 1. Penicillium expansum strains used in this study

\begin{tabular}{lll}
\hline Strain $^{\mathrm{a}}$ & \multicolumn{1}{c}{ Genotype } & \multicolumn{1}{c}{ Source } \\
\hline $\mathrm{Pe}-21$ & Wild-type $P$. expansum, Israel & Hadas et al. (2007) \\
GOX2-RNAi strains: $\mathrm{TPe}_{130}, \mathrm{TPe}_{141}, \mathrm{TPe}_{114}, \mathrm{TPe}_{116}$ & RNAi gox1:gox2:hygR & Barad et al. (2012) \\
$I D H$-RNAi strains: $\mathrm{TPe}_{17}, \mathrm{TPe}_{77}$ & RNAi idh:hygR & $\ldots$ \\
$P A C C$-RNAi strains: $\mathrm{TPe}_{34}, \mathrm{TPe}_{109}$ & RNAi pacC:hygR & $\ldots$ \\
\hline
\end{tabular}

a Strains starting with "T" are original transformants. 
Previous reports have indicated a very low level of GLA accumulation in liquid SM buffered with phthalate buffer to $\mathrm{pH}$ 4.5 (Barad et al. 2012; Hadas et al. 2007). These findings were used to clarify the effect of $\mathrm{pH}$ change on GLA and patulin accumulation. For this purpose, the WT and GOX2-RNAi strains were grown in nonbuffered SM-agar medium at an initial $\mathrm{pH}$ of 4.5 compared with 7.0. Growth of the GOX2-RNAi mutants at $\mathrm{pH} 7$ resulted in a significant decrease in patulin production as the level of GLA decreased (Fig. 3B). In this case, the initial $\mathrm{pH}$ of the medium was decreased from 7 to almost 4 by all the different mutants, suggesting that, after $72 \mathrm{~h}$, differential GLA accumulation leads to differential patulin accumulation, even if the final $\mathrm{pH}$ reached by the WT and mutants is approximately 4.0. However, when the fungus was grown at $\mathrm{pH} 4.5$, low levels of patulin were observed in the GOX2-RNAi and WT strains with no changes in medium $\mathrm{pH}$ (Fig. 3A), suggesting that it is not the low pH but the potential for GLA production that determines the accumulation of patulin.

\section{Dynamics of patulin accumulation}

by $G O X 2$-RNAi as function of time and GOX2 expression.

The temporal effect on the differential induction of $\mathrm{pH}$ decline by GOX2-RNAi mutants was studied to determine the importance of the $\mathrm{pH}$ decrease versus GOX2 downregulation on the induction of patulin accumulation. Growth of the WT strain in nonbuffered solid SM at an initial $\mathrm{pH}$ of 7.0 showed a $\mathrm{pH}$ decrease to $6.9,4.3$, and 3.8 after 24,48 , and $72 \mathrm{~h}$, respectively (Fig. 4). This differential induction of $\mathrm{pH}$ decrease was accompanied by a significant increase in patulin accumulation from $0.78 \mu \mathrm{g}$ per gram of DW at $\mathrm{pH} 7$ to $64 \mu \mathrm{g}$ per gram of DW when the $\mathrm{pH}$ decreased to $3.772 \mathrm{~h}$ later. Differential $\mathrm{pH}$ decline by the different GOX2-RNAi mutants all reduced the level of patulin accumulation. At $24 \mathrm{~h}$ after inoculation, when the $\mathrm{pH}$ was still approximately 7 and the level of patulin production by the WT was $0.78 \mu \mathrm{g}$ per gram of DW, 20 and $30 \%$ inhibition of patulin accumulation was induced by the GOX2RNAi mutants impaired in GLA secretion (Fig. 4A). However, $48 \mathrm{~h}$ after inoculation, when the $\mathrm{pH}$ had decreased to almost 4.0 in the WT and 4.5 in the $\mathrm{TPe}_{141}$ mutant, the amount of patulin accumulated increased almost 30-fold in the WT but only 2-fold in the $\mathrm{TPe}_{141}$ mutant, suggesting the importance of incubation time and $\mathrm{pH}$ decline on patulin accumulation and stability. The same pattern was observed when patulin accumulation was determined $72 \mathrm{~h}$ after inoculation. In this case, the $\mathrm{pH}$ decreased by only $0.4 \mathrm{pH}$ units and patulin increased 313-fold in the WT whereas, in the mutants, there was a delayed increase in patulin accumulation. These results indicate that lower accumulation of patulin in GOX2-RNAi strains is largely dependent on the downregulation of GOX2 expression.

The $\mathrm{pH}$ change induced by the WT and the $\mathrm{TPe}_{141}$ GOX2RNAi mutant after $48 \mathrm{~h}$ of growth amounted to only 0.3 units compared with the 18 -fold increase in patulin production by the WT during the same period, again suggesting that $\mathrm{pH}$ alone is not the main factor for patulin induction.

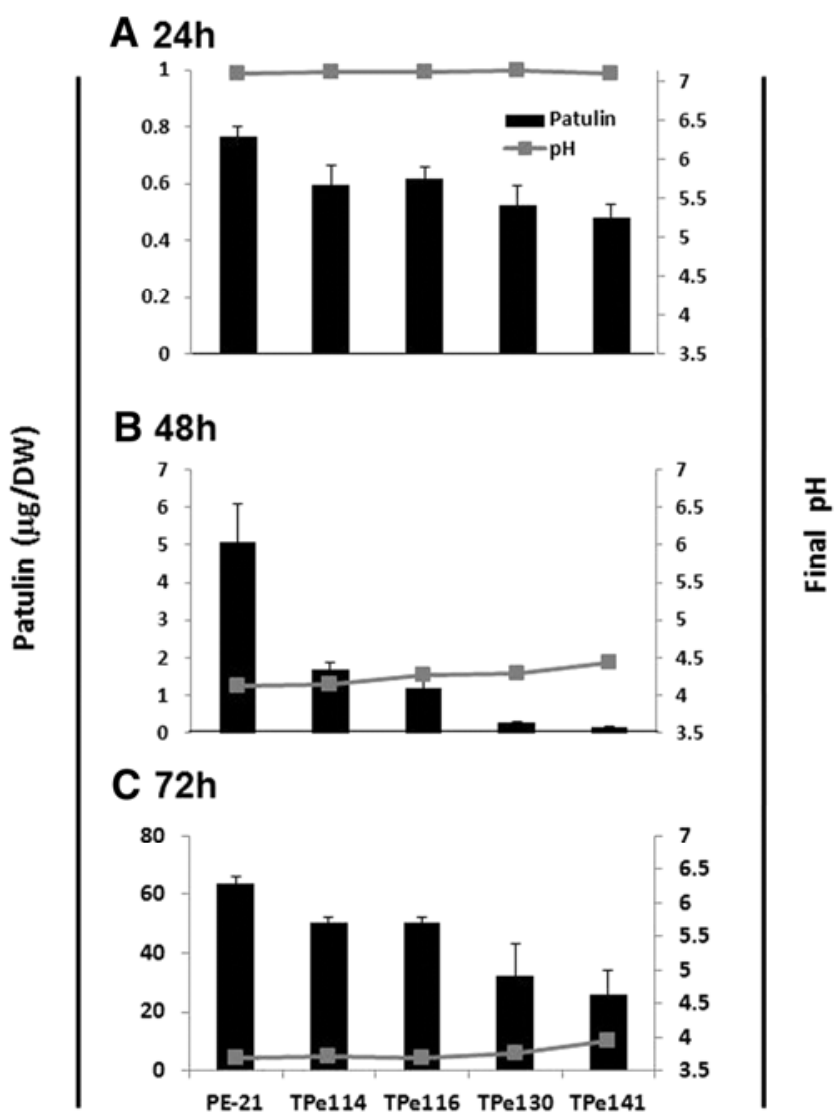

Fig. 4. Dynamics of patulin accumulation by GOX2-RNAi mutants of Penicillium expansum as a function of time. A, Spores of the wild-type Pe21 strain were inoculated into solid secondary medium adjusted to $\mathrm{pH} 7.0$ and sampled 24, B, 48, and C, $72 \mathrm{~h}$ after inoculation. At each sampling date, five agar discs (10 $\mathrm{mm}$ in diameter by $0.5 \mathrm{~mm}$ thick) were extracted for analysis of patulin accumulation. Five replicates were sampled from each strain. Average values \pm standard error of five replicates of patulin extractions are presented. Experiments were repeated three times and the results of a single representative experiment are shown.
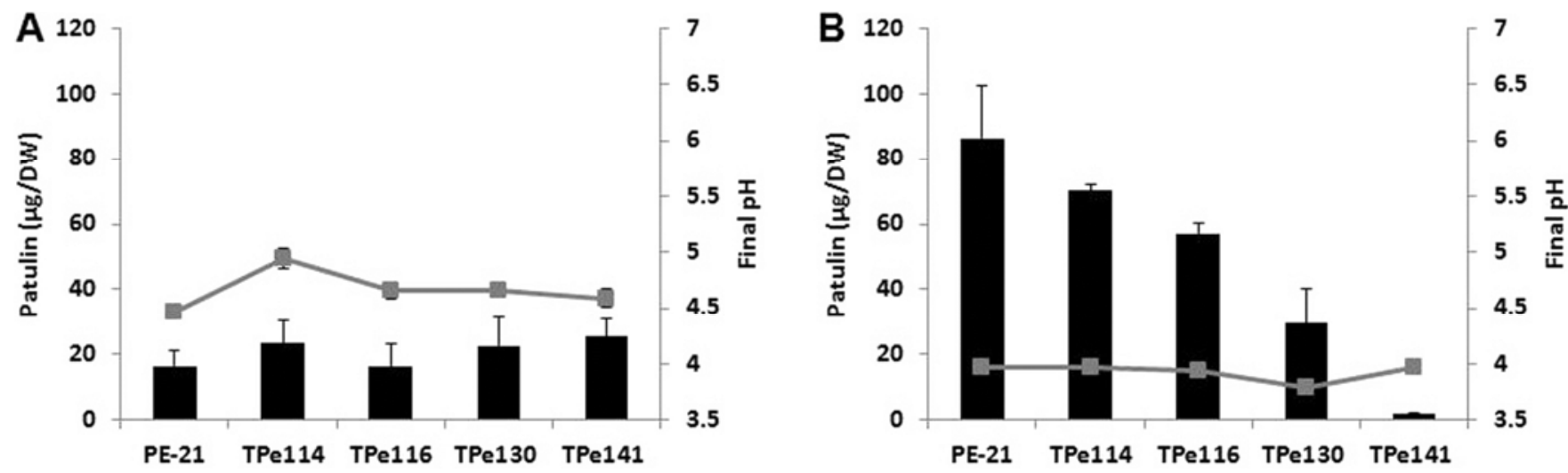

Fig. 3. Relationship between initial $\mathrm{pH}$ and patulin accumulation by the GOX2-RNAi mutants of Penicillium expansum. A, Solid secondary media at an initial $\mathrm{pH}$ of 4.5 or $\mathbf{B}, 7.0$ were inoculated with $100 \mu \mathrm{l}$ of a suspension of $10^{6}$ spores $\mathrm{ml}^{-1}$ and patulin accumulation and final $\mathrm{pH}$ were evaluated $72 \mathrm{~h}$ later by sampling five medium discs from five independent culture plates. Average values \pm standard error of five replicates of patulin extractions are presented. Experiments were repeated three times and the results of a single representative experiment are shown. 
Analysis of the precursors for patulin production by Grootwassink and Gaucher (1980) indicated the importance of glucose as a carbon source on patulin accumulation. Growth with increasing concentrations of glucose from 25 to $50 \mathrm{mM}$ in $0.2 \mathrm{M}$ phosphate-buffered medium at $\mathrm{pH} 7.0$ (Fig. 5A to $\mathrm{C}$ ) showed, in all cases, maximal accumulation of GLA by $48 \mathrm{~h}$ followed by an increase in patulin $24 \mathrm{~h}$ later concomitant with a decrease in GLA concentration. This increase in patulin accumulation was accompanied by an activation of $I D H$. These and previous results of Bork and associates (1998) and Ramachandra and associates (2006) suggested that the $\beta$-gluconate, gluconic acid may be metabolized to patulin through glycolysis. To further support this hypothesis, the WT strain was grown in the presence of GLA as sole carbon source. Growth of the WT for $72 \mathrm{~h}$ indicated that GLA, under the afore-described conditions, is consumed (reduction in the media) (Fig. 5A) and metabolized to patulin (increase in the media) (Fig 5B) through the activation of $I D H$ expression (Fig. 5C). Interestingly, growth of the WT strain in the presence of sucrose as sole carbon source induced almost 10 -fold more patulin than that obtained with a similar concentration of glucose in culture (results not shown). This indicates that GLA and other sugars induce the accumulation of patulin with different efficiencies.

The relationship between patulin and pathogenicity.

Previous findings indicated that acidification of the fruit host environment via the accumulation of GLA enhances
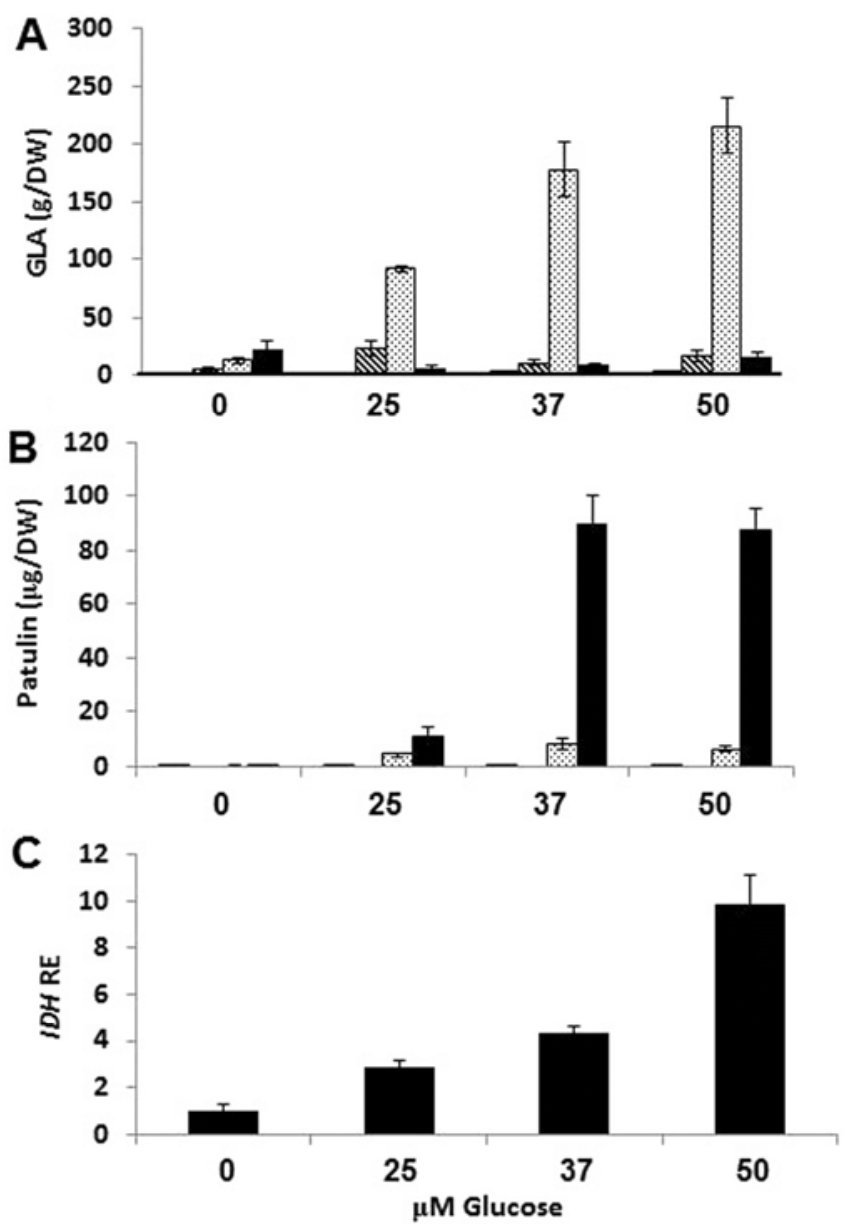

Pepg1 gene expression in $P$. expansum, resulting in enhanced maceration and colonization of the fruit by the fungus (Barad et al. 2012; Hadas et al. 2004). Our present findings indicate that GOX2-RNAi mutants with reduced pathogenicity show reduced GLA and patulin accumulation. These results raise the question of the possible contribution of patulin to $P$. expansum pathogenicity. To analyze this, we developed IDH-RNAi mutants (Fig. 6A). In total, 87 hygromycin-resistant transformants were purified to single spores on hygromycin B selection medium, and several rounds of hyphal transfer from the edge of the colony were performed. The transformants were tested for relative expression of $I D H 48 \mathrm{~h}$ after transfer to GLA-inducing $\mathrm{SM}$ at $\mathrm{pH}$ 7.0.

Physiological analysis of the $I D H$-RNAi mutants revealed growth and sporulation patterns similar to those of the WT strain when they were grown on potato dextrose agar (PDA). Putative IDH-RNAi transformants were confirmed by polymerase chain reaction (PCR) screening with FHyg and RHyg primers (Tables 1 and 2; Fig. 6B). Characterization of the WT and $I D H$-RNAi mutants showed that they did not differ significantly in GLA accumulation, and $\mathrm{pH}$ reduction after $48 \mathrm{~h}$ was similar for the WT, control vector strain, and IDH-RNAi mutants $\mathrm{TPe}_{17}$ and $\mathrm{TPe}_{77}$ (Fig. 6D); however, the mutants showed an $87.5 \%$ decrease in patulin accumulation (Fig. 6E). Analysis of the colonization pattern in fruit showed 28 and $12 \%$ inhibited colonization by $\mathrm{TPe}_{17}$ and $\mathrm{TPe}_{77}$, respectively (Fig. 6F), suggesting that patulin also contributes to $P$. expansum patho-
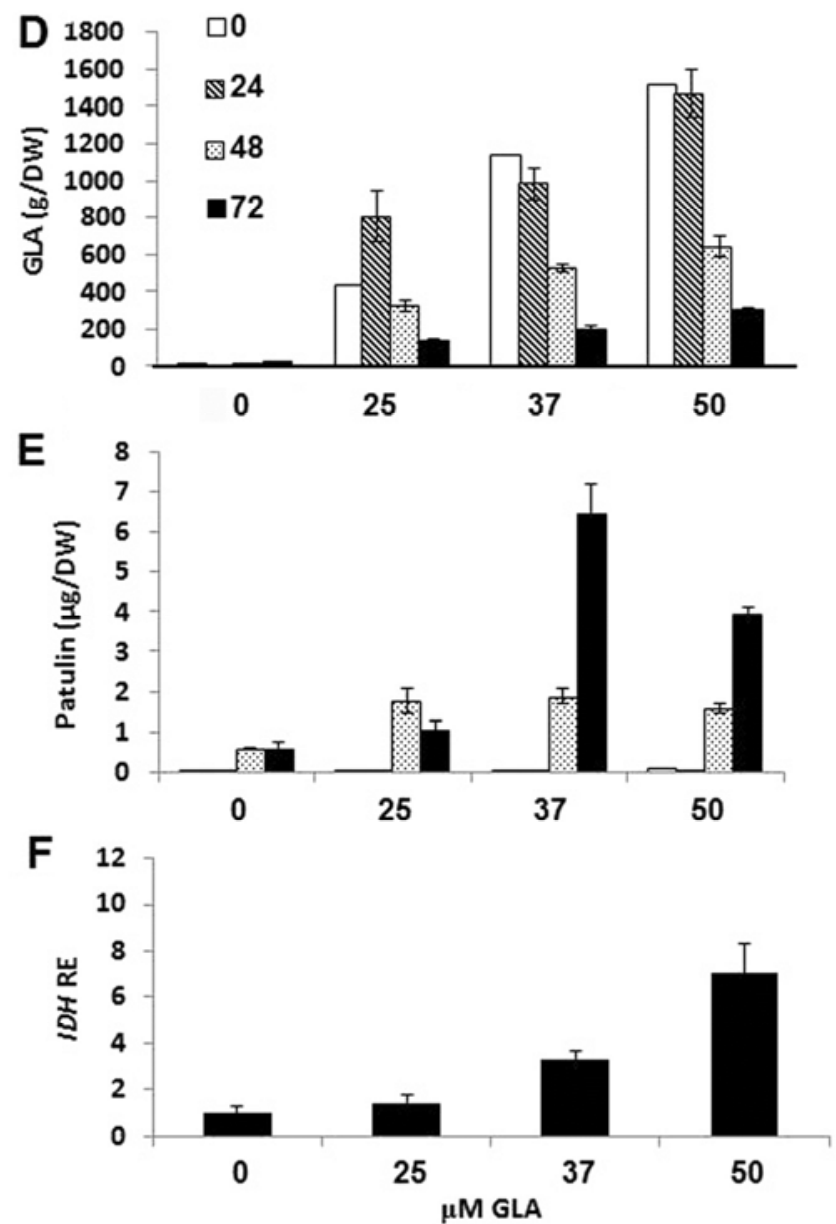

Fig. 5. Accumulation of D-gluconic acid (GLA), relative $I D H$ expression, and patulin in solid secondary medium (SM) using increasing concentrations of A to $\mathbf{C}$, glucose and D to F, GLA as carbon sources. Spores of isolate Pe-21 were inoculated into $0.2 \mathrm{M}$ phosphate-buffered solid SM-agar adjusted to pH 7.0, and disc samples were taken $0,24,48$, and $72 \mathrm{~h}$ later. Five replicates were sampled for each substrate. Average values \pm standard error of five replicates of GLA, relative $I D H$ expression, and patulin extractions are presented. Experiments were repeated three times and the results of a single representative experiment are shown. 
genicity. Patulin's ability to directly induce cell death and, in this way, contribute to fungal colonization was detected when apple fruit were treated with the mycotoxin at 50 and $100 \mu \mathrm{g}$ $\mathrm{ml}^{-1}$ (Supplementary Fig. S1). Results indicated a three- to fourfold increase in cell death on the apple tissue, confirming early findings by Riley and Showker (1991) in animal tissue.

\section{Differential modulation of GLA and patulin accumulation and pathogenicity by PACC-RNAi mutants.}

To confirm the global regulation of GLA and patulin accumulation under changing $\mathrm{pH}$, the relative expressions of $P$. expansum $P A C C, G O X 2$, and $I D H$ were analyzed under nonbuffered conditions at $\mathrm{pH} 4$ and 7. Growth of the WT strain on solid GLA-inducing medium at $\mathrm{pH} 7$ resulted in overexpression of PACC, GOX, and IDH compared with Penicillium spp. grown at $\mathrm{pH} 4.0$ (Fig. 7). These results suggest a dependence on alkaline conditions for activation of GOX2 and $I D H$ for the accumulation of GLA and patulin.

Functional analysis of the downregulation of $G O X 2$ and $I D H$ and its effect on GLA and patulin accumulation and pathogenicity was carried out following downregulation of the transcription factor PACC, involved in the activation of genes
Table 2. Oligonucleotides used in this study

\begin{tabular}{ll}
\hline Oligonucleotide & \multicolumn{1}{c}{ Sequence $\mathbf{5}^{\prime} \rightarrow \mathbf{3}^{\prime}$} \\
\hline F28S & GGAACGGGACGTCATAGAGG \\
R28S & AGAGCTGCATTCCCAAACAAC \\
RGOX2 371 & GGGCGTGTCCAGGAACC \\
FGOX2 290 & TTCACAACCGCACCGAGA \\
FIDH-RT & TACTGTGCTCGAACCGTCAC \\
RIDH-RT & TCTTTGCTAGCGACATCGAA \\
F_Idh_SnabI+SphI & TGGGTACGTAAGCAATGGCATGCCATA \\
& AGTTCC \\
R_Idh_StuI+XhoI & TCAATCGCTGTTCCTCGAGCAGGCCTCA \\
& TTCCG \\
FPACC-RT & ACGAATTCTTTGGCGACTTG \\
RPACC-RT & CATTGAGGAAGGGAAGCTGA \\
F_pacC_SnabI+SphI & TGTACGTAAAAGTACCAACAACCTCAG \\
& CATGCCCTG \\
R_pacC_StuI+XhoI & GACCCTCGAGGAAGGGAAGCTGAAAGG \\
& CCTGCAAAC \\
Fhyg & GTCCTGCGGGTAAATAGCTG \\
Rhyg & ATTTGTGTACGCCCGACAGT \\
gox Fwd single & GAACGGAGGTACCTGGACTCGAGCACA \\
gox Rev single & CAAGGC \\
& CCACAAGTCAAGCTTTAGCATGCCAGCG \\
\hline
\end{tabular}

D

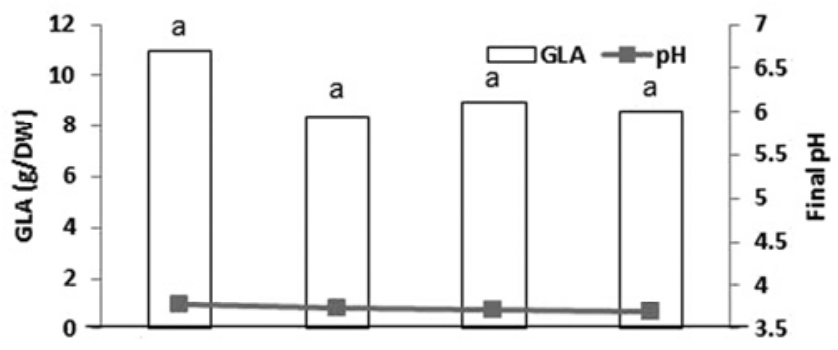

E

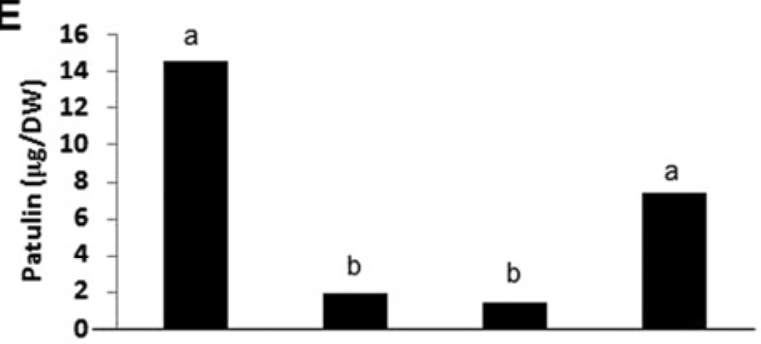

$\mathbf{F}$

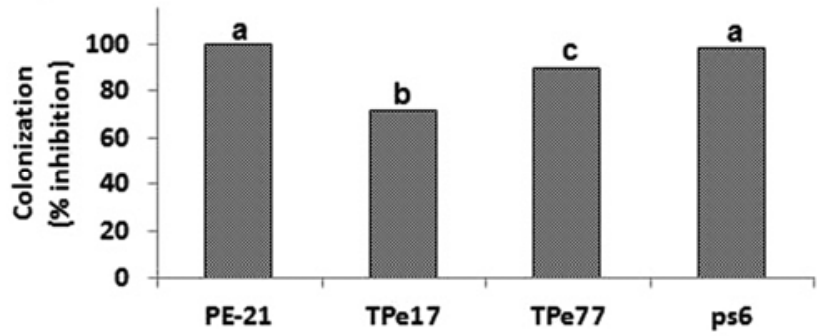

Fig. 6. Patulin and D-gluconic acid (GLA) accumulation, relative $I D H$ expression, and pathogenicity on 'Golden Delicious' apple fruit induced by $I D H$ RNAi mutants of Penicillium expansum. A, Development of IDH-RNAi mutants using the psilent- 1 plasmid to generate silenced $I D H$ gene by using the inverted-repeat transgene of the $I D H$ sequence; $\mathbf{B}$, downregulated $I D H$ TPe mutants were confirmed by amplification of a 0.75 -kb polymerase chain reaction product of the hygromycin (Hyg) resistance gene; $\mathbf{C}$, comparative relative IDH expression; D, GLA accumulation; E, patulin accumulation; F, colonization by the wild-type, the $I D H$-RNAi mutants $\mathrm{TPe}_{17}$ and $\mathrm{TPe}_{77}$, and the control vector strain ps6. Spores of the different strains were inoculated onto solid secondary medium-agar adjusted to $\mathrm{pH} 7.0$, and samples were taken $48 \mathrm{~h}$ later. Five agar discs ( $10 \mathrm{~mm}$ in diameter by $0.5 \mathrm{~mm}$ thick) were extracted for analysis of GLA and patulin accumulation. Five replicates were sampled for each strain. Average values \pm standard error of five replicates of relative $I D H$ expression are presented. Comparisons of inhibition of patulin and GLA culture extractions, and colonized diameter from three inoculations of Pe-21 and of the $I D H$ RNA $i$ mutants, were carried out on the same apple. Columns and symbols with different letters are significantly different at $P \leq 0.05$ according to the TukeyKramer multiple comparison test. Experiments were repeated three times and the results of a single representative experiment are shown. 
modulated by pH, using RNAi technology (Fig. 8A). In total, 120 hygromycin-resistant transformants were purified to single spores on hygromycin B selection medium, and several rounds of hyphal transfer from the edge of the colony were performed. The transformants were tested for relative $P A C C$ expression $3 \mathrm{~h}$ after transfer to GLA-inducing $\mathrm{SM}$ at $\mathrm{pH}$ 7.0. Two PACC-RNAi transformants- $-\mathrm{TPe}_{34}$ and $\mathrm{TPe}_{109}$-that were found to downregulate relative $P A C C$ expression, were used for further characterization. Putative PACC-RNAi transformants were confirmed by PCR screening with FHyg and RHyg primers (Tables 1 and 2; Fig. 8B). PCR analysis of the PACCRNAi transformants $\mathrm{TPe}_{34}$ and $\mathrm{TPe}_{109}$ (Table 1) generated the expected 750-kb PCR fragment (Fig. 8B).

Physiological analysis of the $P A C C$-RNAi mutants revealed growth and sporulation patterns similar to those of the WT strain when they were grown on PDA. Functional characterization of $P A C C$-RNAi mutants during growth on SM adjusted to
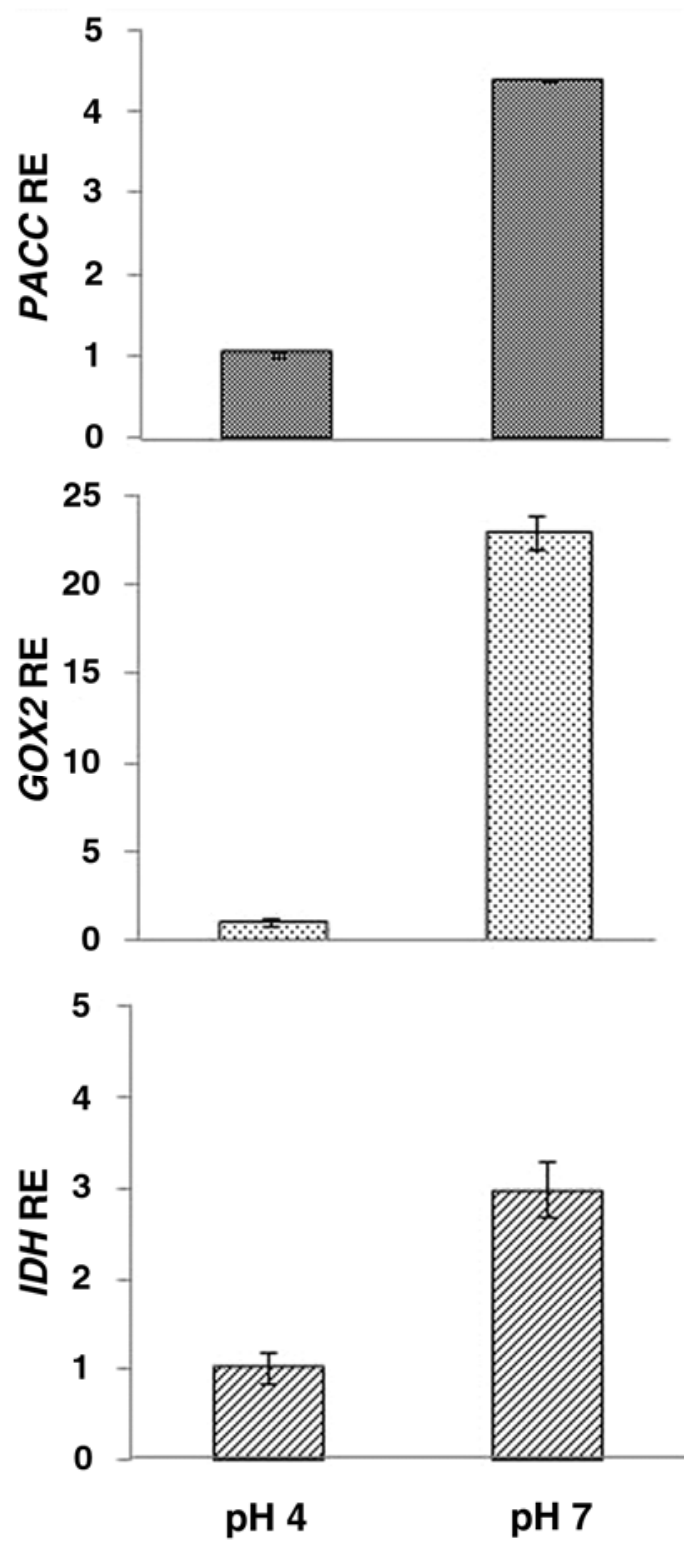

Fig. 7. Relative gene expression (RE) of GOX2, IDH1, and PACC of Penicillium expansum determined by quantitative reverse-transcription polymerase chain reaction at $\mathrm{pH} 4$ and 7 . Average \pm standard error of relative expression of three selected $P$. expansum genes on the second day of growth on solid secondary medium. Experiments were repeated three times and the results of a single representative experiment are shown.
pH 7.0 showed significant downregulation of PACC (by 44 and $72 \%$ for $\mathrm{TPe}_{109}$ and $\mathrm{TPe}_{34}$ mutants, respectively) compared with the WT Pe-21 and the transformant control vector (Fig. $8 \mathrm{C})$. The downregulation of relative $P A C C$ expression by the $\mathrm{TPe}_{34}$ and $\mathrm{TPe}_{109}$ mutants reduced disease development by 46 and $40 \%$, respectively, 5 days after inoculation of 'Golden Delicious' apple fruit (Fig. 8F). Moreover, PACC-RNAi mutants $\mathrm{TPe}_{34}$ and $\mathrm{TPe}_{109}$ showed a 63 and $27 \%$ reduction, respectively, in GLA production (Fig. 8D) and a 92 and $95 \%$ reduction, respectively, in patulin accumulation 2 days after inoculation of SM-solid plates adjusted to $\mathrm{pH} 7$ (Fig. 8E). These results indicate that, whereas downregulation of $I D H$ only reduces patulin accumulation without affecting GLA levels, downregulation of GOX2 reduces both GLA and patulin accumulation and has an additive effect on the mutants' reduction in pathogenicity.

\section{DISCUSSION}

\section{pH and patulin production.}

Patulin is a common secondary metabolite present in decayed tissue colonized by $P$. expansum and other Penicillium spp. (Puel et al. 2010). Following inoculation of the P. expansum isolate Pe-21, we detected the accumulation of GLA at $2.5 \mu \mathrm{g}$ per gram of $\mathrm{FW}$ in the colonized tissue, expression of the gene encoding the last enzyme of patulin biosynthesis $(I D H)$, and patulin accumulation to a concentration of $8.0 \mu \mathrm{g}$ per gram of FW decayed tissue. Barad and associates (2012) suggested that pathogenicity of $P$. expansum is modulated by changes in $\mathrm{pH}$ mediated by GLA accumulation as a factor for activation of polygalacturonase under acidic conditions. However, the joint accumulation in the colonized tissue of two fungal metabolites, GLA and patulin, raised the question of their contribution, either separately or synergistically, to P. expansum pathogenicity.

Our first approach to analyze the contribution to pathogenicity of the accumulated GLA and patulin was to modulate GLA accumulation by GOX2-RNAi mutants. Using a series of GOX2-RNAi mutants, Barad and associates (2012) demonstrated that downregulation of GOX2 is accompanied by impairment in the ability to produce GLA and apple colonization. Using the same mutants, we observed that the higher the impairment in GLA accumulation, the higher the inhibition of relative $I D H$ expression and patulin accumulation. Impairment in the ability to produce GLA by $98 \%\left(\mathrm{TPe}_{141}\right.$ compared with the WT) was accompanied by $90 \%$ downregulation in the relative expression of $I D H$ and $94 \%$ reduction in patulin accumulation (from 11.6 to $0.5 \mu \mathrm{g}$ per gram of DW) (Fig. 2B). The question was whether the low $\mathrm{pH}$ or the dynamic process of GLA accumulation that enhances the $\mathrm{pH}$ decrease is the factor that activates $I D H$ overexpression and patulin accumulation. To answer this question, we cultured the GOX2-RNAi mutants of $P$. expansum with differential capabilities of acidification (Barad et al. 2012) in solid media at initial pH of 4.5 and 7.0. Growth at $\mathrm{pH} 4.5$ was previously shown by Barad and associates (2012) and Hadas and associates (2007) to inhibit the accumulation of GLA. In our experiments, growth at $\mathrm{pH} 4.5$ eliminated the differential expression of GOX2 in the GOX2 mutants and reduced patulin accumulation to similar low levels in all mutants. In contrast, if the GOX2-RNAi mutants were cultured at an initial $\mathrm{pH}$ of 7.0, the differential activation of GOX2 led to differential accumulation of GLA and patulin (Fig. 2), confirming the earlier reports indicating enhanced expression of GOX2 at high pH (Barad et al. 2012; Hadas et al. 2007). These results suggest that the concurrent dynamic $\mathrm{pH}$ regulation by GLA accumulation and not low $\mathrm{pH}$ per se is the critical factor in the induction of this secondary metabolism of patulin production and fungal colonization. 
To demonstrate the cumulative effect of differential $G O X 2$ expression on patulin accumulation as a function of time, the GOX2-RNAi mutants were cultured at an initial $\mathrm{pH} 7$ for 24 , 48, and $72 \mathrm{~h}$. Under these conditions, differential GOX2 expression was directly related to patulin accumulation in each of the three sampling periods. In all of the sampling periods, $98 \%$ decreased accumulation of GLA in the GOX2-RNAi mutant $\mathrm{TPe}_{141}$ reduced patulin production by $56 \%$ after $72 \mathrm{~h}$. Interestingly, only a $0.2 \mathrm{pH}$ unit difference was observed between the WT and the mutant with the most reduced pathogenicity, where a $100 \%$ increase in level of patulin was observed. This supports our previous finding that it is not the final $\mathrm{pH}$ of the medium but fungal exposure to the dynamic GLA-accumulation process that is important for the induction of patulin production.

The metabolic capability for patulin accumulation by $P$. expansum under conditions of GLA accumulation and decreasing $\mathrm{pH}$ suggests that GLA might be one of the precursors for patulin's biosynthetic accumulation. This might explain McCallum and associates' (2002) results where, without knowing the cause for the $\mathrm{pH}$ decrease, they found that more aggressive isolates of $P$. expansum greatly reduce the $\mathrm{pH}$ of the growth medium and produce detectable levels of patulin, whereas the weaker growers produce a smaller reduction in $\mathrm{pH}$ and no detectable patulin. To further determine the relationship between GLA and patulin, $P$. expansum was grown in the presence of sucrose, glucose, or GLA as sole carbon source, with sucrose being the most efficient precursor for patulin accumulation. Increasing concentrations of glucose increased the accumulation of GLA followed by patulin 1 day later. Growth on glucose yielded accumulation of higher amounts of patulin than growth on GLA, indicating that, whereas different substrates might behave as metabolic precursors for patulin, they differ in their efficiencies. Interestingly, few reports have referred to the sources for carbon metabolism for patulin biosynthesis (Puel et al. 2010). Like aflatoxin, glucose is an optimal carbohydrate source for patulin production but it is unclear whether the carbon source directly induces patulin production or modulates its biosynthesis through general metabolism. The present results indicate that glucose and GLA act as substrate precursors for patulin production with differential efficiency. Previously, Ramachandra and associates (2006) suggested that the GLA may be metabolized to patulin through glycolysis to pyruvate and, from there, probably via general metabolism to
A

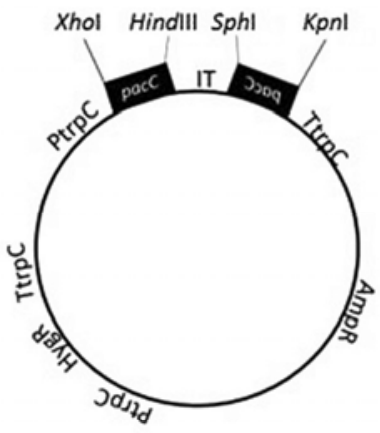

B
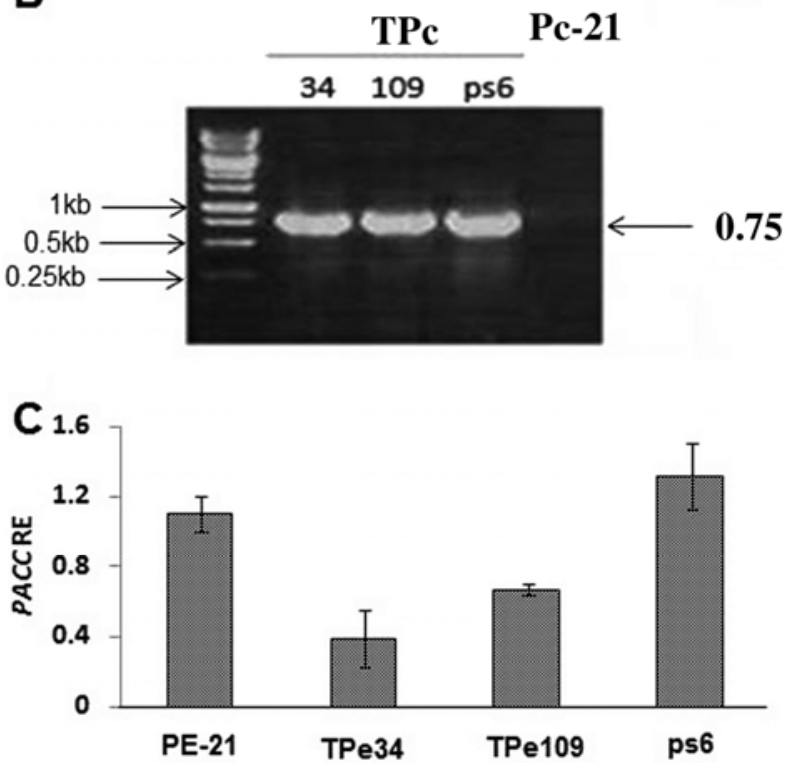
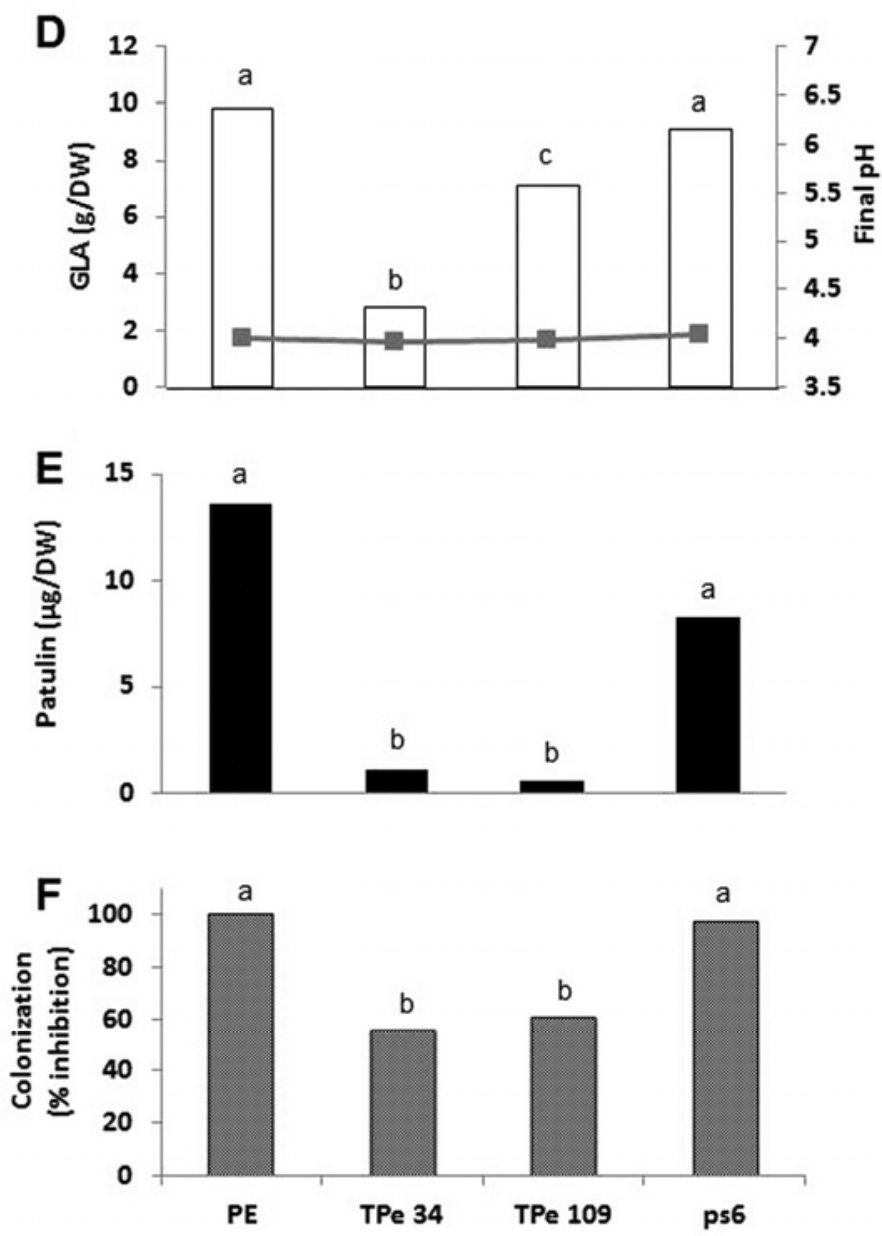

Fig. 8. Patulin and D-gluconic acid (GLA) accumulation, relative $P A C C$ expression, and pathogenicity on 'Golden Delicious' apple fruit induced by $P A C C$ RNAi mutants of Penicillium expansum. A, Development of PACC-RNAi mutants using the psilent-1 plasmid to generate silenced $P A C C$ using the invertedrepeat transgene of the $P A C C$ sequence; $\mathbf{B}$, downregulated $P A C C$ TPe mutants were confirmed by amplification of a $0.75-\mathrm{kb}$ polymerase chain reaction product of the hygromycin (Hyg) resistance gene; $\mathbf{C}$, comparative relative PACC expression; D, GLA accumulation; E, patulin accumulation; F, colonization of wild-type, $P A C C$-RNAi mutants $\mathrm{TPe}_{34}$ and $\mathrm{TPe}_{109}$, and the control vector $\mathrm{TPe}_{6}$. Spores of the different strains were inoculated onto solid secondary mediumagar-containing plates adjusted to $\mathrm{pH} 7.0$ and samples were taken $48 \mathrm{~h}$ later. Five agar discs ( $10 \mathrm{~mm}$ in diameter by $0.5 \mathrm{~mm}$ thick) were extracted for analysis of GLA and patulin accumulation. Five replicates were sampled for each strain. Average values \pm standard error of five replicates of $P A C C$ expression are presented. Comparisons were carried out of inhibition of patulin and GLA culture extractions and colonization by three inoculations of Pe-21 and the $P A C C$ RNAi mutants on the same apple. Columns and symbols with different letters are significantly different at $P \leq 0.05$ according to the Tukey-Kramer multiple comparison test. Experiments were repeated three times and the results of a single representative experiment are shown. 
patulin, suggesting the importance of GLA accumulation during early stages of $P$. expansum colonization of fruit as a precursor for patulin accumulation (Barad et al. 2012; Hadas et al. 2007).

\section{GLA, patulin and pathogenicity.}

Our second approach to differentiating the contributions to pathogenicity of the accumulated GLA and patulin was to modulate patulin accumulation using $I D H$-RNAi mutants. No differences were found in GLA accumulation or $\mathrm{pH}$ modulation by the $I D H$-RNAi mutants versus the control strains when grown at an initial $\mathrm{pH}$ of 7.0. However, whereas the WT, control vector, and $I D H$-RNAi mutants all produced a similar level of GLA (8.5 to $11.0 \mathrm{~g}$ per gram of DW) and similarly reduced the $\mathrm{pH}$ from 7 to almost 3.6, the $I D H$-RNAi mutants reduced patulin accumulation by almost $85 \%$ and pathogenicity by 12 to $28 \%$ (Fig. 6). These results confirmed the claim of Sanzani and associates (2012) that knockout of 6-MSAS, an enzyme involved in the first committed step of patulin biosynthesis, inhibits fungal colonization. Those mutants, obtained by genedisruption technique, continued to produce 68 to $59 \%$ of the patulin produced by the WT strain, leading to a 34 and $54 \%$ reduction in disease incidence and severity, respectively. In our work, downregulation of $I D H$ by almost $92 \%$ reduced patulin production by almost $89 \%$ but reduced colonization by only 12 to $28 \%$; this suggested that, although patulin contributes to the process of colonization, it has a lower effect than the level of colonization inhibition reported by the knockout of 6-MSAS in the $P$. expansum strain used by Sanzani and associates (2012). The phenotypic response of the host to patulin accumulation is reasonable considering the previously reported cytotoxic cell response, which was thought to indicate that patulin contributes to fungal colonization by enhancing cell death (Barhoumi and Burghardt 1996; Riley and Showker 1991), and this was confirmed in apple tissue. These results indicate that the observed accumulation of patulin is an independent factor modulating pathogenicity of $P$. expansum. However, the contribution of patulin to pathogenicity is enhanced under increased accumulation of GLA, as observed during colonization of the fruit tissue.

\section{The effect of acidification by GLA accumulation on patulin and pathogenicity of $P$. expansum.}

Several reports have already indicated that the production of secondary metabolites is determined by generic factors and associated cellular regulatory systems, such as the global nitrogen, carbon, and $\mathrm{pH}$ regulatory systems common to most fungi (Yu and Keller 2005). Nitrogen and carbon source and low $\mathrm{pH}$ play key roles in the regulation of sterigmatocystin or aflatoxin production in Aspergillus spp. (Kachholz and Demain 1983; Keller et al. 1997a; Woloshuk et al. 1997). In Aspergillus nidulans, low $\mathrm{pH}$ is required for sterigmatocystin production, whereas alkaline $\mathrm{pH}$ is required for penicillin production (Keller et al. 1997a; Shah et al. 1991). Low pH is also conducive to the production of fumonisin by Fusarium proliferatum (Keller et al. 1997b) and ochratoxin by A. ochraceus (O'Callaghan et al. 2006). There are no published reports on $\mathrm{pH}$ modulation as a factor in $P$. expansum pathogenicity. However, the higher expression of $G O X 2$ and $I D H$ at $\mathrm{pH} 7$ compared with $\mathrm{pH} 4$ suggested that pathogenicity factors that modulate $P$. expansum colonization might be regulated by the transcription factor PACC. At acidic $\mathrm{pH}$, the PACC protein is in an inactive conformation and is unable to bind to the promoter sites of the target genes but, under alkaline growth conditions, activated $P A C C$ acts as both an activator of alkalineexpressed genes and a repressor of acid-expressed genes (Penalva et al. 2008). Loss-of-function mutations in PACC cause an acidity-mimicking phenotype and result in increased expression of "acid" genes and reduced expression of "alkaline" genes, as was found for Colletotrichum gloeosporioides (Miyara et al. 2012). Under neutral or alkaline conditions, PACC has been reported to regulate many genes in A. nidulans, $P$. chrysogenum (Denison 2000; Eisendle et al. 2004; Espeso and Arst 2000), C. gloeosporioides (Miyara et al. 2008, 2010), and Sclerotinia sclerotiorum (Kim et al. 2008), as was found for $P$. expansum. In $S$. sclerotiorum, which regulates acidification of the environment with oxalic acid, site-directed mutagenesis of pacl created a dominant activating pacl ${ }^{c}$ mutation that resulted in the activation of pacl, leading to oxalic acid accumulation that was largely independent of ambient $\mathrm{pH}$ (Kim et al. 2008). This indicated a positive role for pacl in oxalic acid regulation. Functional analysis of $P A C C$-RNAi mutants of $P$. expansum was used as our third approach to determining the contributions of GLA and patulin during pathogenicity and $\mathrm{pH}$ regulation by PACC. PACC-RNAi mutants reduced GLA and patulin accumulation and produced a $45 \%$ reduction in pathogenicity, while the $\mathrm{pH}$ decreases in the WT and mutants were similar. These results suggest that, in $P$. expansum, $P A C C$ has a significant role in both factors that modulate pathogenicity (i.e., GLA and patulin accumulation). These results are similar to those obtained with Sclerotinia spp., whose oxalic acid production increased with increasing ambient pH (Maxwell 1973; Rollins 2003; Rollins and Dickman 2001). In P. expansum, $P A C C$ also displayed $\mathrm{pH}$-regulated expression, its steady-state levels increasing with growth medium $\mathrm{pH}$. How GLA and patulin accumulation are regulated during fungal pathogenicity in fruit is still not clear. However, aside from the effect of GLA on patulin accumulation, previous work has indicated that nitrogen level may regulate the expression of patulin metabolism. Grootwassink and Gaucher (1980) suggested that a distinct metabolic profile can be expressed in cultures containing ammonium as the nitrogen source. When ammonium ions were added to cultures producing patulin, rapid downregulation of $I D H$ and 6-MSAS transcripts and patulin accumulation was observed (Rollins and Gaucher 1994). Maceration of fruit tissue by pectolytic enzymes may lead to differential accumulation of nitrogen precursors that affect pathogen metabolism, as was reported for the downregulation of sterigmatocystin and ochratoxin A (Abbas et al. 2009; Feng and Leonard 1998). These changes might explain, in part, the significant differences in patulin accumulation, given the differential nitrogen contents of host fruit. Further research is needed to fully understand the mechanism governing the downregulation of genes modulating patulin biosynthesis. The presence of several putative GATA sites along the upstream regions of both the $6 M S A S$ and $I D H$ genes of $P$. griseofulvum, which might interact with a global nitrogen regulatory factor encoded by the $n r f a$ gene (an AreAorthologous gene), was suggested as a possible mechanism for the modulation of patulin accumulation (Ellis 1996).

In summary, GLA appears to play a central role in $\mathrm{pH}$ responsiveness. Its production is a $\mathrm{pH}$-regulated process and its accumulation, by virtue of environmental acidification, may serve as a regulator of acid $\mathrm{pH}$-regulated processes such as PG1 expression (Hadas et al. 2007; Prusky et al. 2004). On the other hand, $P$. expansum uses GLA accumulation during modification of the ambient $\mathrm{pH}$ environment as a regulatory cue for disease and accumulation of secondary metabolites such as patulin.

\section{MATERIALS AND METHODS}

Fungal strains and culture conditions.

The WT $P$. expansum isolate Pe-21 was obtained from decayed apple fruit (Malus domestica 'Golden Delicious') pur- 
chased from a local market in Israel (Hadas et al. 2007). Cultures were grown at $27^{\circ} \mathrm{C}$ in the dark and maintained on PDA plates (Difco, Detroit) unless otherwise indicated. Conidia were harvested with $10 \mathrm{ml}$ of sterile distilled water supplemented with $0.01 \%$ (vol/vol) Tween 80 (Sigma-Aldrich, Copenhagen, Denmark). When required, hygromycin B (Roche, Branchburg, NJ, U.S.A.) at $250 \mu \mathrm{g} \mathrm{ml}^{-1}$ was added to the growth medium. Cells were visualized with a model BX60F-3 microscope and a model SZ-60 stereoscope (both from Olympus America, Inc., Melville, NY, U.S.A.).

\section{Assay for colonization and disease development.}

To assess disease development, 'Golden Delicious' apple fruit were inoculated by placing $5 \mu \mathrm{l}$ of a conidial suspension containing $10^{6}$ spores per milliliter on each of six 2-mm deep, 2-mm diameter wounds spaced around a circle on the upper part of the stem end of the fruit. Following inoculation, the fruit were incubated at $25^{\circ} \mathrm{C}$ in covered plastic containers containing wet paper towels until decay symptoms developed.

\section{Analysis and quantification of total GLA production by $P$. expansum.}

To evaluate total GLA (i.e., free GLA and D-glucono- $\delta$-lactone) level in all of the transformant cultures, $10^{6}$ fungal spores per milliliter were inoculated into $40 \mathrm{ml}$ of a primary medium, (i.e., glucose minimal medium [GMM]) in 125-ml flasks containing (per liter) $10 \mathrm{~g}$ of glucose, $5 \mathrm{~g}$ of yeast extract (Difco), $50 \mathrm{ml}$ of nitrate salts, and $1 \mathrm{ml}$ of trace elements, at $\mathrm{pH} 6.5$. The cultures were incubated at $25^{\circ} \mathrm{C}$ with shaking at $150 \mathrm{rpm}$ for $48 \mathrm{~h}$. Cultures were harvested by vacuum filtration through a sterile Büchner funnel fitted with a filter paper (Whatman No. 1), and the remaining mycelia were washed twice with 50 $\mathrm{ml}$ of sterile distilled water. The washed mycelia were resuspended in $50 \mathrm{ml}$ of GLA-inducing SM containing (per liter) 60 $\mathrm{g}$ of sucrose, $7 \mathrm{~g}$ of $\mathrm{NaNO}_{3}, 3 \mathrm{~g}$ of tryptone (Difco), $1 \mathrm{~g}$ of $\mathrm{KH}_{2} \mathrm{PO}_{4}, 0.5 \mathrm{~g}$ of $\mathrm{MgSO}_{4} \cdot 7 \mathrm{H}_{2} \mathrm{O}$, and $0.5 \mathrm{~g}$ of $\mathrm{KCl}$, adjusted to $\mathrm{pH}$ 7.0. The culture was incubated at $25^{\circ} \mathrm{C}$ on a rotating shaker at $150 \mathrm{rpm}$ for $48 \mathrm{~h}$, unless otherwise specified. For experiments with modified $\mathrm{pH}$, the initial $\mathrm{pH}$ of the $\mathrm{SM}$ was adjusted to the desired level with either $10 \mathrm{~N} \mathrm{NaOH}$ or concentrated $\mathrm{HCl}$. After $48 \mathrm{~h}$ of growth, aliquots of the suspensions were collected and the amounts of GLA produced were measured with an enzymatic method for measuring total GLA content (free GLA and D-glucono- $\delta$-lactone) (Boehringer Mannheim, Tokyo) according to the manufacturer's instructions. Similarly, mycelium was frozen in liquid nitrogen and lyophilized for dry weight determination or RNA extraction. To check the GLA concentration in SM-agar media, five $1-\mathrm{cm}^{2}$-diameter discs were placed in $5 \mathrm{ml}$ of sterilized water and homogenized with an HG-300 homogenizer (MRC, Calgary, Canada). A 1-ml aliquot of the solution was sampled into a 1.5-ml Eppendorf tube and was centrifuged for $5 \mathrm{~min}$ at $20,800 \times g$. The supernatant was taken for GLA analysis.

\section{Analysis and quantification of patulin production by $P$. expansum.}

To evaluate the patulin level in culture, $100 \mu \mathrm{l}$ of a $10^{6}$ fungal spores per milliliter solution was grown on 55 -mm-diameter petri dishes containing $10 \mathrm{ml} \mathrm{SM}$-agar for $48 \mathrm{~h}$ at $27^{\circ} \mathrm{C}$ (unless otherwise specified). Five discs of $1 \mathrm{~cm}^{2}$ in diameter were added to $5 \mathrm{ml}$ of sterilized water and homogenized by HG-300 homogenizer. Patulin was extracted twice with $10 \mathrm{ml}$ of ethyl acetate by shaking for 1 min using a vortex mixer and centrifuging for $5 \mathrm{~min}$ at room temperature at 3,200 $\times \mathrm{g}$. The organic phase was extracted with $10 \mathrm{ml}$ of a $1.5 \%$ sodium carbonate solution by shaking for 1 min using a vortex mixer and centrifuging for $5 \mathrm{~min}$ at room temperature, $3,200 \times g$. The sample was completely dried, redissolved in $0.5 \mathrm{ml}$ of the elution solution $0.02 \mathrm{M}$ ammonium acetate and acetonitrile (9:1, $\mathrm{vol} / \mathrm{vol}$ ), and filtered through a $0.2-\mu \mathrm{m}$ Minisart filter (Sartorius Stedim, Goettingen, Germany) before injecting into the column. Quantitative analysis of patulin was performed by a high-performance liquid chromatograph (HPLC) (HitachiMerck, Dartford, U.K.) equipped with a UV-VIS detector at $280 \mathrm{~nm}$, with an RP-18 5- $\mathrm{mm}$ column (Merck, Amsterdam). The concentrate $(50 \mu \mathrm{l})$ was injected to the HPLC equipped with a C18, 250-by-4.6-mm, Microsorb-MV-100-5 column, at a rate of $0.8 \mathrm{ml} / \mathrm{m}$. The patulin fraction was eluted with $0.02 \mathrm{M}$ ammonium acetate and acetonitrile $(9: 1, \mathrm{vol} / \mathrm{vol})$ with a retention time of approximate 7 min. Results were compared with a commercial patulin standard (Sigma-Aldrich).

\section{pH measurements.}

$\mathrm{pH}$ was measured with a double-pore slim electrode (Hamilton, Reno, NV, U.S.A.) connected to a Thermo Orion Model $720 \mathrm{~A}$ Plus $\mathrm{pH}$ meter. The $\mathrm{pH}$ of the medium was measured in the homogenized disc plate or in the Erlenmeyer with liquid media.

\section{Nucleic acid analysis.}

Extraction of DNA from fungi, restriction-enzyme digestion, and gel electrophoresis were performed by standard methods (Sambrook et al. 1989). DNA extraction was carried out using the MasterPure Yeast DNA Purification Kit (Epicentre Biotechnologies, Madison, WI, U.S.A.). RNA extraction was carried out using the SV Total RNA Isolation kit (Promega, Madison, WI, U.S.A.). Purity of the extracted RNA was assayed by the ND-1000 spectrophotometer (NanoDrop Technologies Inc., Wilmington, DE, U.S.A.), and the RNA was then stored at $-80^{\circ} \mathrm{C}$ until further analysis.

\section{Construction and characterization of $P A C C$ - and $I D H$-RNAi mutants.}

To assess the functions of pacC, we developed strains in which $P A C C$ or $I D H$ was silenced by RNAi technology using the inverted-repeat transgene of the $P A C C$ or $I D H$ sequence (Barad et al. 2012). The silencing vector pSilent-1 (Nakayashiki et al. 2005) was used to generate the $P A C C$-RNAi or IDH-RNAi constructs. A 580-bp fragment of pacC and $647 \mathrm{bp}$ of $I D H$ with no predicted introns were amplified using the primers $\mathrm{F}_{-}$pacC_ SnabI+SphI, R_pacC_StuI+XhoI and F_idh_SnabI+SphI, R_idh_StuI+XhoI, respectively. The resulting fragments contained the engineered restriction sites $5^{\prime}$ pacC SnabI/SphI and $3^{\prime}$ pacC StuI/XhoI or 5'idh SnabI/SphI and 3'idh StuI/XhoI, respectively. First, the restriction sites $S p h \mathrm{I}$ and $S t u \mathrm{I}$ were used to insert the fragment in the forward orientation into pSilent-1. Next, the restriction sites SnabI and XhoI were used to insert the fragment in the reverse orientation. The resulting plasmid was used for Pe-21 transformation.

Fungal transformation of protoplasts was performed essentially according to Miller and associates (1985). In short, spores $\left(5 \times 10^{7}\right)$ originated from 7-day-old cultures were germinated in GMM for $8 \mathrm{~h}$ and filtered through Whatman No. 1 paper. The collected spores were then transferred to a filtered $(0.45-\mu \mathrm{m}$ filter) enzyme mixture prepared in $15 \mathrm{ml}$ of osmotic medium (147.9 $\mathrm{g} \mathrm{MgSO}_{4}$ in $10 \mathrm{mM} \mathrm{NaPO}_{4}$ buffer adjusted to $\mathrm{pH} 5.8$ in $500 \mathrm{ml}$ ) containing $0.1 \mathrm{~g}$ of lysing enzyme from Trichoderma harzianum (Sigma-Aldrich), $0.05 \mathrm{~g}$ of cellulose from A. niger (Fluka Japan, Tokyo), $0.1 \mathrm{~g}$ of novozyme (InterSpex Products, Inc., Foster City, CA, U.S.A.), and $0.1 \mathrm{~g}$ of Yatalase (Takara, Shiga, Japan). The spores were shaken overnight at $27^{\circ} \mathrm{C}$ and $50 \mathrm{rpm}$ and transferred to osmotic buffer that enabled the protoplast collection. The protoplasts were then transformed as reported by Miller and associates (1985). Strains exhibiting 
impaired expression of the gene were tested by PCR for the presence of the hygromycin fragment: a $0.75-\mathrm{kb}$ PCR fragment was obtained by using forward and reverse primers from the hygromycin cassette (Fhyg and Rhyg, respectively) (Table 2).

\section{Gene-expression analysis}

\section{by quantitative reverse-transcription PCR analysis.}

To examine gene expression, cultures of the WT isolate Pe-21 and RNAi mutants were cultured as indicated above for measurement of GLA level. RNA was extracted from 80-mg samples of frozen mycelia with the SV Total RNA isolation kit. The reverse-transcription reaction was performed on $1 \mu \mathrm{g}$ of total RNA with the Reverse-it First-Strand Synthesis Kit (Abgene, Surrey, U.K.), and cDNA samples were diluted 1:10 (vol/vol) with ultrapure water.

Real-time quantitative PCR was performed with the RotorGene 3000 system (Corbett Research, Cambridgeshire, U.K.). PCR amplification was performed with $3.4 \mu \mathrm{l}$ of cDNA template in $10 \mu \mathrm{l}$ of a reaction mixture containing $6.6 \mu \mathrm{l}$ of mix from the SYBR Green Amplification Kit (ABgene) and 300 $\mathrm{nM}$ primers: the forward and reverse primers for the GOX 2 amplicon were FGOX2-290 and RGOX2-371, respectively; those for the IDH amplicon were FIDH-RT and RIDH-RT, respectively; those for the PACC amplicon were FPACC-RT and RPACC-RT, respectively; and those for the 28S rRNA of $P$. expansum were F28S and R28S, respectively (Table 2). Results were analyzed with the Rotor-Gene 6 software. The $28 \mathrm{~S}$ rRNA gene served as an endogenous control and the calibration sample varied according to the experiment, as indicated. A mixture of all cDNAs was used in all treatments as a template for calibration curves designed for each pair of primers, to verify that a single PCR product had been formed. Relative quantification was calculated with the $\Delta \Delta \mathrm{C}_{\mathrm{T}}$ method (Livak and Schmittgen 2001). The $\Delta \mathrm{C}_{\mathrm{T}}$ value was determined by subtracting the cycle threshold $\left(\mathrm{C}_{\mathrm{T}}\right)$ results for the target gene from those for the endogenous control gene and normalized against the calibration sample to generate the $\Delta \Delta C_{T}$ values. Each experiment was performed in triplicate, and three different biological experiments were conducted. One representative set of results is presented. Mean values of $2^{-\Delta \Delta C T} \pm$ standard error of each treatment were subjected to mean comparisons by least significant difference (LSD), according to the TukeyKramer multiple comparison test at $P<0.05$.

\section{Statistical analysis.}

Data were analyzed with the JMP software package (version 3.2.6; SAS Institute, Cary, NC, U.S.A.). Mean comparisons of GOX2 expression, GLA and patulin production, and ambient $\mathrm{pH}$ measurements were analyzed according to LSD, with the Tukey-Kramer multiple comparison test at $P \leq 0.05$. Frequencies of germination were pooled for each set of three replications per treatment or isolate, after application of Student's $t$ test to determine homogeneity of variance among the three independent experiments, and no statistically significant $(P \leq$ 0.05) differences among experiments were found.

\section{LITERATURE CITED}

Abbas, A., Valez, H., and Dobson, A. D. 2009. Analysis of the effect of nutritional factors on OTA and OTB biosynthesis and polyketide synthase gene expression in Aspergillus ochraceus. Int. J. Food Microbiol. 135:22-27.

Barad, S., Horowitz, S., Sherman, L., and Prusky, D. 2012. Penicillium expansum glucose oxidase-encoding gene, gox2, is essential for gluconic acid production and acidification during colonization of deciduous fruits. Mol. Plant-Microbe Interact. 25:779-788.

Barhoumi, R., and Burghardt R. C. 1996. Kinetic analysis of the chronology of patulin and gossypol-induced cytotoxicity in vitro. Fundam.
Appl. Toxicol. 30:290-297.

Bork, P., Dandekar, T., Diaz-Lazcoz, Y., Eisenhaber, F., Huynen, M., and Yuan, Y. 1998 Predicting function: From genes to genomes and back. J. Mol. Biol. 283:707-725.

Bruchmana, E. E., Schach H., and Graf, H. 1987. Role and properties of lactonase in a cellulase system. Biotechnol. Appl. Biochem. 9:146-159.

Demirci, M., Arici, M., and Gumus, T. 2003. Presence of patulin in fruit and fruit juices produced in Turkey. Ernaehr. Umsch. 50:262-263.

Denison, S. H. 2000. pH regulation of gene expression in fungi. Fungal Genet. Biol. 29:61-71.

Dombrink-Kurtzman, M. A. 2007. The sequence of the isoepoxydon dehydrogenase gene of the patulin biosynthetic pathway in Penicillium species. Antonie Leeuwenhoek. 91:179-189.

Eisendle, M., Oberegger, H., Zadra, I., and Haas, H. 2004. Biosynthesis and uptake of siderophores is controlled by the pacC-mediated ambient $\mathrm{pH}$ regulatory system in Aspergillus nidulans. Eukaryot. Cell 3:561563.

Ellis, C. M. 1996. Regulation of polyketide gene expression: The isolation and function of nitrogen regulatory factor, NRFA from Penicillium urticae. Ph.D. thesis, University of Calgary, Calgary, Alberta, Canada.

Espeso, E. A., and Arst, H. N., Jr. 2000. On the mechanism by which alkaline $\mathrm{pH}$ prevents expression of an acid-expressed gene. Mol. Cell. Biol. 20:3355-3363.

Feng, G. H., and Leonard, T. J. 1998. Culture conditions control expression of the genes for aflatoxin and sterigmatocystin biosynthesis in Aspergillus parasiticus and A. nidulans. Appl. Environ. Microbiol. 64:2275-2277.

Grootwassink, J. W., and Gaucher, G. M. 1980. De novo biosynthesis of secondary metabolism enzymes in homogeneous cultures of Penicillium urticae. J. Bacteriol. 141:443-455.

Hadas, Y., Goldberg, I., Pines, O., and Prusky, D. 2007. Involvement of gluconic acid and glucose oxidase in the pathogenicity of Penicillium expansum in apples. Phytopathology 97:384-390.

Kachholz, T., and Demain, A. L. 1983. Nitrate repression of averufin and aflatoxin biosynthesis. J. Nat. Prod. 46:499-506.

Keller, N. P., Nesbitt, C., Sarr, B., Phillips, T. D., and Burow, G. B. 1997a. $\mathrm{pH}$ regulation of sterigmatocystin and aflatoxin biosynthesis in Aspergillus spp. Phytopathology 87:643-648.

Keller, S. E., Sullivan, T. M., and Chirtel, S. 1997b. Factors affecting the growth of Fusarium proliferatum and the production of fumonisin B1: Oxygen and pH. J. Ind. Microbiol. Biotechnol. 19:305-309.

Kim, K. S., Min, J.-Y., and Dickman, M. B. 2008. Oxalic acid is an elicitor of plant programmed cell death during Sclerotinia sclerotiorum disease development. Mol. Plant-Microbe Interact. 21:605-612.

Kobayashi, M., Shinohara, M., Sakoh, C., Kataoka, M., and Shimizu, S. 1998. Lactone-ring cleaving enzyme: Genetic analysis, novel RNA editing and evolutionary implications. Proc. Natl. Acad. Sci. U.S.A. 95:12787-12792.

Larsen, T. O., Frisvad, J. C., Ravn, G., and Skaaning, T. 1998. Mycotoxin production by Penicillium expansum on blackcurrant and cherry juice. Food Addit. Contam. 15:671-675.

Leggott, N. L., and Shephard, G. S. 2001. Patulin in South African commercial apple products. Food Control 12:73-76.

Livak, K. J., and Schmittgen, T. D. 2001. Analysis of relative gene expression data using real-time quantitative PCR and the $2-\Delta \Delta C T$ method. Methods 25:402-408.

Lugauskas, A., Repeckiene, J., and Novosinskas, H. 2005. Micromycetes, producers of toxins, detected on stored vegetables. Ann. Agric. Environ. Med. 12:253-260.

Maxwell, D. P. 1973. Oxalate formation in Whetzelinia sclerotiorum by oxaloacetate acetylhydrolase. Physiol. Mol. Plant Pathol. 3:279-288.

McCallum, L., Tsao, R., and Zhou, T. 2002. Factors affecting patulin production by Penicillium expansum. J. Food Prot. 65:1937-1942.

Miller, B. L., Miller, K. Y., and Timberlake, W. E. 1985. Direct and indirect gene replacement in Aspergillus nidulans. Mol. Cell Biol. 5:17141721

Miyara, I., Shafran, H., Kramer Haimovich, H., Rollins, J., Sherman, A. and Prusky, D. 2008. Multifactor regulation of pectate lase secretion by Colletotrichum gloeosporioides pathogenic on avocado fruits. Mol. Plant Pathol. 9:281-291.

Miyara, I., Shafran, H., Davidzon, M., Sherman, A., and Prusky, D. 2010. $\mathrm{pH}$ regulation of ammonia secretion by Colletotrichum gloeosporioides and its effect on appressorium formation and pathogenicity. Mol. PlantMicrobe Interact. 23:304-316.

Miyara, I., Shnaiderman, C., Meng, X., Vargas, W. A., Diaz-Minguez., J. M., Thon, M., and Prusky, D. 2012. Role of nitrogen-metabolism genes expressed during pathogenicity of the alkalinizing Colletotrichum gloeosporioides and their differential expression in acidifying pathogens. Mol. Plant-Microbe. Interact. 25:1251-1263.

Mohammad-Saeid, J., García-Estrada, C., Barreiro, C., Cuadrado, A. A. 
Salehi-Najafabad, Z., and Martín, J. F. 2010. Proteome analysis of the penicillin producer Penicillium chrysogenum. Mol. Cell Proteom. 9:2729-2744.

Nakayashiki, H., Hanada, S., Quoc, N. B., Kadotani, N., Tosa, Y., and Mayama, S. 2005. RNA silencing as a tool for exploring gene function in ascomycete fungi. Fungal Genet. Biol. 42:275-283.

O'Callaghan, J., Stapleton, P. C., and Dobson, A. D. W. 2006. Ochratoxin A biosynthetic genes in Aspergillus ochraceus are differentially regulated by $\mathrm{pH}$ and nutritional stimuli. Fungal Genet. Biol. 43:213-221.

Penalva, M. A., Tilburn, J., Bignell, E., and Arst, H. N., Jr. 2008. Ambient $\mathrm{pH}$ gene regulation in fungi: Making connections. Trends Microbiol. 16:291-300.

Piemontese, L., Solfrizzo, M., and Visconti, A. 2007. Occurrence of patulin in conventional and organic fruit products in Italy and subsequent exposure assessment. Food Addit. Contam. 22:437-442.

Prusky, D., and Yakoby, N. 2003. Pathogenic fungi: Leading or led by ambient pH? Mol. Plant Pathol. 4:509-516.

Prusky, D., McEvoy, J. L., Saftner, R., Conway, W. S., and Jones, R. 2004 The relationship between host acidification and virulence of Penicillium spp. on apple and citrus fruit. Phytopathology 94:44-51.

Puel, O., Galtier, P., and Oswald, I. P. 2010. Biosynthesis and toxicological effects of patulin. Toxins 2:613-631.

Qin, G., Tian, S., Chand, Z., and Li, B. 2007. Crucial role of antioxidant proteins and hydrolytic enzymes in pathogenicity of Penicillium expansum. Mol. Cell. Proteom. 6:425-438.

Ramachandra, S., Fontanille, P., Pandey, A., and Larroche, C. 2006. Gluconic acid: Properties, applications and microbial production. Food Technol. Biotechnol. 44:185-195.

Reddy, K. R. N., Spadaro, D., Lore, A., Gullino, M. L., and Garibaldi, A. 2010. Potential of patulin production by Penicillium expansum strains on various fruits. Mycotox. Res. 26:257-265.

Riley, R. T., and Showker, J. L. 1991. The mechanism of patulin's cytotoxicity and the antioxidant activity of indole tetramic acids. Toxicol. Appl. Pharmacol. 109:108-126.
Ritieni, A. 2003. Patulin in Italian commercial apple products. J. Agric Food Chem. 51:6086-6090.

Rollins, J. A. 2003. The Sclerotinia sclerotiorum pac1 gene is required for sclerotial development and virulence. Mol. Plant-Microbe Interact. 16:785-795.

Rollins, J. A., and Dickman, M. B. 2001. pH signaling in Sclerotinia sclerotiorum: Identification of a pacC/RIM1 homolog. Appl. Environ. Microbiol. 67:75-81.

Rollins, M. J., and Gaucher, G. M. 1994, Ammonium repression of antibiotic and intracellular proteinase production in Penicillium urticae. Appl. Microbiol. Biotechnol. 41:447-455.

Sambrook, J., Fritsch, E. F., and Maniatis, T. 1989. Molecular Cloning: A Laboratory Manual. Cold Spring Harbor Laboratory Press, Cold Spring Harbor, NY, U.S.A.

Sánchez-Torres, P., and González-Candelas, L. 2003. Isolation and characterization of genes differentially expressed during the interaction between apple fruit and Penicillium expansum. Mol. Plant Pathol. 4:447-457.

Sanzani, S. M., Reverberi, M., Punelli, M., Ippolito, A., and Fanelli, F. 2012. Study on the role of patulin on pathogenicity and virulence of Penicillium expansum. Int. J. Food Microbiol. 153:323-331.

Sekiguchi, J., and Gaucher, G. M. 1977. Conidiogenesis and secondary metabolism in Penicillium urticae. Appl. Environ. Microbiol. 33:147-158.

Shah, A. J., Tilburn, J., Adlard, M. W., and Arst, H. N., Jr. 1991. pH regulation of penicillin production in Aspergillus nidulans. FEMS (Fed. Eur. Microbiol. Soc.) Microbiol. Lett. 61:209-212.

Woloshuk, C. P., Cavaletto, J. R., and Cleveland, T. E. 1997. Inducers of aflatoxin biosynthesis from colonized maize kernels are generated by an amylase activity from Aspergillus flavus. Phytopathology 87:164-169.

Yao, C., Conway, W. S., and Sams, C. E. 1996. Purification and characterization of a polygalacturonase produced by Penicillium expansum in apple fruit. Phytopathology 86:1160-1166.

Yu, J. H., and Keller, N. 2005. Regulation of secondary metabolism in filamentous fungi. Annu. Rev. Phytopathol. 43:437-458. 